\title{
Aging and amnesia: A running span analysis
}

\author{
STANLEY R. PARKINSON \\ Arizona State University, Tempe, Arizona 85281
}

\begin{abstract}
Groups of young $(\mathrm{N}=36)$, old $(\mathrm{N}=7)$, and amnesic Korsakoff patients $(\mathrm{N}=6)$ were tested with a running memory span procedure. The running span task was administered with a fast presentation rate $(2$ digits/sec) under passive listening instructions to minimize the contribution of secondary or rehearsed memory. The young recalled with greater accuracy than subjects in the old and amnesic groups. These results are inconsistent with the hypothesis that storage and retrieval deficits in aging and amnesia are limited to secondary memory. Rather, they suggest that memory impairment in these populations is more extensive than is often maintained.
\end{abstract}

In immediate free recall, subjects generally recall the terminal itenıs first and then shift to the reproduction of items from the beginning of the list. This recall pattern yields large primacy and recency effects over initial and terminal positions, respectively, and asymptotic performance over the positions in the middle of the series. Retention functions of this type are often described by a dual store model (e.g., Waugh \& Norman, 1965) in which terminal serial position performance is mediated by a store of limited capacity (primary memory) and initial and middle serial positions reflect the contribution of a large-capacity store (secondary memory).

During recent years the immediate free recall task and the dual store model have been of interest to investigators attempting to classify the nature of memory deficits associated with both normal aging and amnesia. For example, Craik (1968) compared the performances of old and young subjects in free recall and found that young subjects recalled with greater accuracy than old subjects on all types of verbal material tested (ranging from digits to unrelated words). Using a method developed by Murdock (1967) for estimating primary and secondary memory components, Craik found that age differences were restricted to secondary memory.

Comparable findings have been obtained in experiments with amnesic patients. Baddeley and Warrington (1970) found that amnesic patients (primarily alcoholic Korsakoff) recalled with lower accuracy than controls on all but the last two positions of 10-item lists. Based on the difference between immediate and delayed recall, Baddeley and Warrington concluded that storage deficits in amnesic patients were confined to secondary memory. Similar conclusions were drawn from experiments on another group of amnesic patients (alcoholic Korsakoff and encephalitic) by Brooks and Baddeley (1976).

While the aforementioned results are consistent with

This research was supported in part by Grant MH 26870 from the National Institute of Mental Health. Requests for reprints should be sent to Stanley R. Parkinson, Department of Psychology, Arizona State University, Tempe, Arizona 85281. the hypothesis that storage deficits in amnesic Korsakoff patients and the aged are restricted to secondary memory, other findings suggest that memory impairment in these populations is less circumscribed. For example, Arenberg (1976) tested groups of old and young in immediate free recall and found that young subjects recalled with greater accuracy than old subjects on both beginning and terminal serial positions. In another study, Cermak, Naus, and Reale (1976) found that amnesic Korsakoff patients recalled with lower accuracy than controls on all but the terminal position of 20 -item lists. Within the confines of the primary-secondary model, the results of Arenberg with the aged and of Cermak et al. with amnesics suggest that memory impairment in these populations embraces both primary and secondary memory components.

The extent to which primary memory is impaired in amnesics and in the aged was investigated further in the present research with a running memory span procedure (Pollock, Johnson, \& Knaff, 1959). List length is varied in the running span task and subjects are instructed to recall a number of items from the end of the list. In previous work with the running span task, Talland $(1965,1968)$ found deficits in the performances of both amnesics and the aged. It is tempting to conclude that these findings indicate impairment of primary memory; however, slow presentation rates were used in both sets of experiments (1 item/2 sec with amnesics and 1 item/ sec with the aged). Hockey (1973) found an interaction between presentation rate and grouping instructions in running memory span; retention of terminal positions was most accurate with a passive listening strategy at fast presentation rates, whereas overall performance with an active grouping strategy was best with slow rates. This interaction suggests the possibility of secondary memory involvement with slow rates, and this could have been a factor mediating the performance decrements in Talland's studies. In the present experiment, performances of amnesic Korsakoff patients, young controls, and senior citizens were compared in a running memory span task. Fast presentation rates and passive 
listening strategies were employed to maximize the contribution of primary memory.

\section{METHOD}

\section{Subjects}

Three groups of subjects participated in this experiment. The young group consisted of 36 Arizona State University students. The amnesic group was composed of six males with an average age of 58.8 years (range $=47-70$ years). Amnesic patients were diagnosed as amnesic Korsakoff of alcoholic etiology by the neurology service of the Boston Veterans Administration Hospital. The old group consisted of seven males with an average age of 73.6 years (range $=65-80$ years). Subjects in the old group were volunteers from Phoenix chapters of the American Association of Retired People. Both young and old groups were run at Arizona State University; amnesic patients were run at the Boston, Brockton, and Bedford Veterans Administration Hospitals in Massachusetts.

\section{Stimuli and Procedure}

Stimulus lists were constructed from the set of digits $0-9$. The order of digits within lists was random, with the following restrictions: (1) No digit could be repeated more than twice per series, and repetitions of digits were spaced; and (2) no natural runs (forward or backward) longer than three digits were permitted. Fifteen test lists were made, five each with list lengths of 5,10 , and 15 digits. Subjects were instructed that list length would vary from trial to trial and that they should recall the last five items backward starting with the terminal item. Instructions emphasized that items would be counted as correct only if they were written in the correct column. Rehearsal and grouping were discouraged by instructing subjects to think of only one item at a time during stimulus presentation. Stimulus lists were presented at a rate of 2 digits/sec, and the interval between lists was self-paced.

\section{RESULTS}

A strict serial recall scoring procedure was employed in data analysis. The data displayed in Figure 1 are typical for running memory span with fast presentation rates and a passive listening strategy (Hockey, 1973); that is, retention of the terminal item was near perfect, and accuracy on other positions was an inverse function of the distance from the end of the list.

Both old and amnesic subjects recalled with lower accuracy than the young. Comparisons between old and young groups revealed a main effect of group $[\mathrm{F}(1,41)=$ $7.33, \mathrm{p}<.01]$ and a Group by Serial Position interaction $[F(4,164)=3.29, p<.01]$. The same pattern of results was obtained for comparisons between amnesic Korsakoff patients and young subjects [for the group effect, $F(1,40)=13.91, p<.001$; for the Group by Serial Position interaction, $F(4,160)=7.91, p<.001]$. Subsequent serial position analyses yielded reliable linear trends for both sets of comparisons. The linear component interacted with group in both comparisons, with amnesic patients $(p<.001)$ and old subjects $(p<.02)$ exhibiting steeper slopes than the young. As depicted in Figure 1, there was a tendency for the old group to recall with higher accuracy than amnesic Korsakoff patients, but this was not significant $(F<1)$.

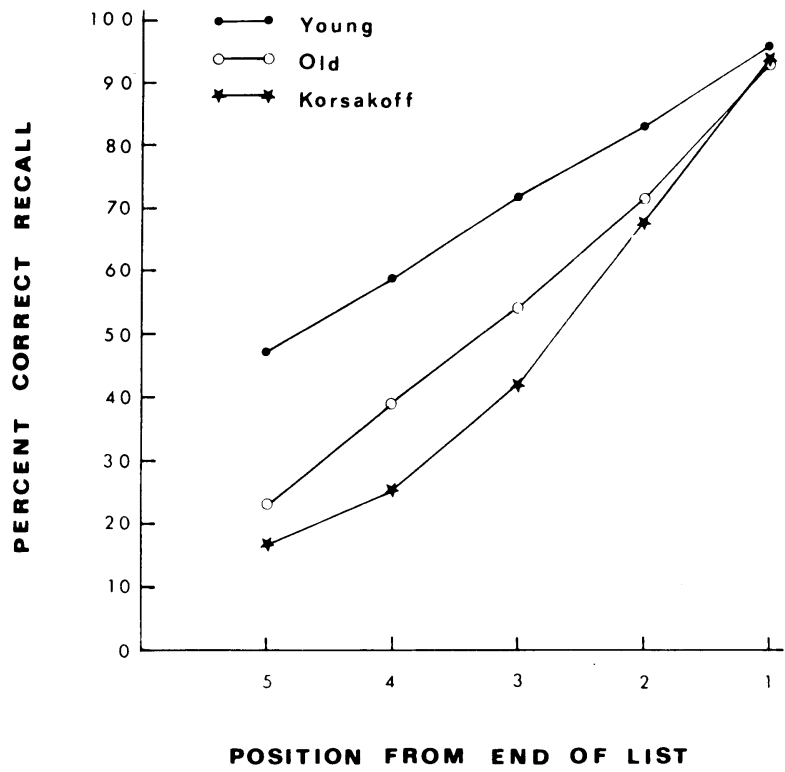

Figure 1. Percent correct recall as a function of serial position for groups of young, old, and amnesic Korsakoff patients in a running memory span task.

\section{DISCUSSION}

In the present experiment, a rapid presentation rate was coupled with an instruction to concentrate on only the most recent item to eliminate secondary or rehearsed memory. The linearity of the functions relating accuracy of recall to serial position suggests that the contribution of secondary memory was indeed minimized or eliminated in this experiment; thus the impairment of performance shown by both amnesics and the aged can be ascribed to a deficit in primary memory. These results are inconsistent with models in which deficits in aging and amnesia are restricted to a secondary memory. The present results should not be taken to imply that amnesics and the aged do not have a deficit in secondary memory, as that has been demonstrated convincingly in the studies cited previously. Rather, the present findings suggest that deficits in these groups extend to more than a single storage system. Other recent studies have shown that sensory memory is also impaired in both amnesics (Cermak \& Butters, 1973) and the aged (Walsh \& Thompson, 1978). Those findings, along with the current results, suggest that memory deficits in these populations are more general than is often maintained.

\section{REFERENCES}

Arenberg, D. The effects of input condition on free recall in young and old adults. Journal of Gerontology, 1976, 31, 551-555.

Baddeley, A. D., \& Warrington, E. K. Amnesia and the distinction between long- and short-term memory. Journal of Verbal Learning and Verbal Behavior, 1970, 9, 176-189.

Brooks, D. N., \& BadDELEY, A. D. What can amnesic patients learn? Neuropsychologia, 1976, 14, 111-122.

Cermak, L. S., \& Butters, N. Information processing deficits of alcoholic Korsakoff patients. Quarterly Journal of Studies on Alcohol, 1973, 34, 1110-1132.

Cermak, L., Naus, M., \& Reale, L. Rehearsal strategies of alcoholic Korsakoff patients. Brain and Language, 1976, 3, 375-385.

Craik, F. I. M. Short-term memory and the aging process. In 
G. A. Talland (Ed.), Human aging and behavior. New York: Academic Press, 1968.

HоскеY, R. Rate of presentation in running memory and direct manipulation of input-processing strategies. Quarterly Journal of Experimental Psychology, 1973, 25, 104-111.

MuRdock, B. B., JR. Recent developments in short-term memory. British Journal of Psychology, 1967, 58, 421-433.

Pollock, I., Johnson, L., \& KnAFF, P. Running memory span. Journal of Experimental Psychology, 1959, 57, 137-146.

Talland, G. A. Deranged memory. New York: Academic Press, 1965.
Talland, G. A. Age and the span of immediate recall. In G. A. Talland (Ed.), Human aging and behavior. New York: Academic Press, 1968.

Walsh, D. A., \& Thompson, L. W. Age differences in visual sensory memory. Journal of Gerontology, 1978, 33, 383-387.

Waugh, N. C., \& Norman, D. A. Primary memory. Psychological Review, 1965, 72, 89-104.

(Received for publication January 13, 1980.) 